See discussions, stats, and author profiles for this publication at: https://www.researchgate.net/publication/296627723

\title{
Incorporation of spirobifluorene regioisomers in electron-donating molecular systems for organic solar cells
}

Article in RSC Advances - March 2016

DOI: 10.1039/C6RA02085B

\section{CITATIONS}

15

9 authors, including:

Ibrahim Bulut

Çanakkale Onsekiz Mart Üniversitesi

70 PUBLICATIONS 417 CITATIONS

SEE PROFILE

2. Sadiara Fall

University of Strasbourg

34 PUBLICATIONS 780 CITATIONS

SEE PROFILE

Some of the authors of this publication are also working on these related projects:

PROOF project View project

Project Organic photovoltaics View project
144

Patricia Chávez

University of Strasbourg

21 PUBLICATIONS 700 CITATIONS

SEE PROFILE

Stephane Méry

French National Centre for Scientific Research

91 PUBLICATIONS 1,405 CITATIONS

SEE PROFILE 


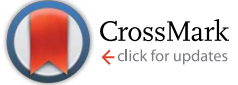

Cite this: RSC Adv., 2016, 6, 25952

Received 23rd January 2016 Accepted 27th February 2016

DOI: $10.1039 / c 6 r a 02085 b$

www.rsc.org/advances

\title{
Incorporation of spirobifluorene regioisomers in electron-donating molecular systems for organic solar cells $\dagger$
}

\author{
Ibrahim Bulut, ${ }^{a}$ Patricia Chávez, ${ }^{a}$ Sadiara Fall, ${ }^{b}$ Stéphane Méry, ${ }^{c}$ Benoit Heinrich, \\ Joëlle Rault-Berthelot, ${ }^{d}$ Cyril Poriel, ${ }^{\star d}$ Patrick Lévêque ${ }^{\star b}$ and Nicolas Leclerc ${ }^{\star a}$
}

\begin{abstract}
We report herein the synthesis and characterizations of new small molecules for organic photovoltaics including diketopyrrolopyrrole and spirobifluorene. Two grafting positions of the spirobifluorene units are used leading to two regioisomers with different optoelectronic properties. Despite, the moderate photovoltaic performances, we show that the incorporation of spirobifluorene as a three-dimension platform into conjugated material backbones allows the increase of dimensionality and brings a more isotropic character to the charge transport properties of the final materials. The solubility is also increased despite the low density of grafted alkyl side-chains, which is an important feature for the future of this technology.
\end{abstract}

\section{Introduction}

In 2009, Nguyen and co-workers demonstrated that organic small molecules can act efficiently as electron-donating species in bulk heterojunction (BHJ) organic solar cells. ${ }^{1}$ Since this seminal work, the field of conjugated small molecules for organic photovoltaics (OPV) has known a continuous growth of interest. At present the best solution-processed solar cells using small molecules as electron-donating species exhibit power conversion efficiencies (PCE) of around 10\%, which is close to the best PCE of polymer-based devices. ${ }^{2}$

Small molecules can fill all the prerequisites for high efficiency solar cells i.e. a broad absorption spectrum and high extinction coefficient, appropriate frontier energy levels and good charge transport properties. Numerous molecular structures have been studied to reach high OPV efficiencies in blends with fullerene derivatives. Diketopyrrolopyrrole (DPP), ${ }^{3}$ bodipy, ${ }^{4}$ merocyanine,${ }^{5}$ squaraine,${ }^{6}$ oligothiophene, ${ }^{7}$ benzodithiophene ${ }^{2 a}$ bophy $^{8}$ and others have been scrutinized as valuable

${ }^{a}$ Institut de Chimie et Procédés pour l'Energie, l'Environnement et la Santé (ICPEES), Département d'Ingénierie Polymère, UMR 7515 associée au CNRS, Ecole Européenne de Chimie, Polymères et Matériaux, 25 rue Becquerel, 67087 Strasbourg, France. E-mail: leclercn@unistra.fr; Tel: +33-3-6885-2709

${ }^{b}$ Laboratoire ICube, Université de Strasbourg, CNRS, 23 rue du Loess, 67037 Strasbourg, France. E-mail: patrick.leveque@unistra.fr; Tel: +33-3-8810-6294

'Institut de Physique et de Chimie des Matériaux de Strasbourg, 23 rue du Loess, BP 84047, 67034 Strasbourg Cedex 02, France

${ }^{d}$ UMR CNRS 6226, Institut des Sciences Chimiques de Rennes, Université de Rennes 1Campus de Beaulieu, 35042 Rennes cedex, France. E-mail: cyril.poriel@univ-rennes1. fr; Tel: +33-2-2323-5977; +33-2-2323-5964

$\uparrow$ Electronic supplementary information (ESI) available. See DOI: 10.1039/c6ra02085b building-blocks for efficient electron-donating small molecules. Most of these molecular systems have a planar elongated structure and their efficiencies in $\mathrm{BHJ}$ devices are based on their strong ability to build an anisotropic $\pi$-stacking edifice. For such electrondonor linear molecules in blend with PCBM fullerene derivatives, the solution deposition often leads to kinetically frozen nonequilibrium and non-optimized nanoscale morphologies with anisotropic charge transport properties. Over the last decade, several studies focused on an alternative approach, which consists to increase the dimensionality of the electron-donor molecules to promote three-dimensional (3D) self-assembled edifices matching with the intrinsically $3 \mathrm{D}$ character of intermolecular interactions with the fullerene acceptor. ${ }^{9}$ Beside the anticipated isotropic optical and charge transport properties of such 3D derivatives, a more stable morphology in blends with PCBM is expected ${ }^{\mathbf{1 0}}$ as well as a higher solubility compared to classical linear $\tau$-stacked molecules. ${ }^{11}$ As a consequence of this improved solubility, the alkyl side-chain density (and all the issues related to their position and nature $^{12}$ ) can be reduced. Moreover, it has been reported that minimizing the alkyl side-chain density can be beneficial for the material optical properties as the concentration of the photoactive material is increased. ${ }^{13}$

Among the interesting non-planar chemical building blocks that have been recently investigated, the spirobifluorene (SBF) moiety, that is the orthogonal connection via a spiro-carbon of two fluorenyl cores, has become an important molecular scaffold in organic electronics. ${ }^{\mathbf{1 4}}$ Indeed, spiroconfigured semiconductors display many characteristics such as high thermal/ morphological and emission colour stability, which are important properties for Organic Light Emitting Diodes (OLED). ${ }^{\mathbf{1 5}}$ Using spiro-carbons to design shape persistent molecules with specific arrangements has been also used in recent years. ${ }^{15-17}$ 
Thus, the SBF core has not only allowed important breakthroughs in the field of OLEDs but has also been investigated as chiral ligand, ${ }^{18,19}$ electropolymerizable unit, ${ }^{20}$ or to construct coordination polymers. ${ }^{21}$ One of the main advantages of the integration of the SBF core in a given material is to limit the intermolecular interactions by keeping a 3D configuration. This strong $\pi$-stacking restriction is known to greatly improve the solubility and processability of the resulting material. ${ }^{22}$ In spite of these promising structural features, the SBF unit remains nearly absent from the OPV literature. ${ }^{23}$

In this report we describe the first use of SBF as a soluble non-planar end-capping group associated to a DPP core and investigate its behaviour as electron-donor in OPV devices. By comparing this molecular architecture to already published molecular systems using identical thiophene-DPP-thiophene (Th-DPP-Th) as central chromophore, ${ }^{1,3 a, 24}$ we demonstrate in particular that excellent solubility and processability can be obtained in a low alkyl side-chain molecular system content, without preventing its crystallization ability.

In order to broaden the understanding of the impact of SBF-containing molecular structure on optoelectronic properties, two positional isomers with a C2 (SBF2-DPP) or a C4 (SBF4-DPP) SBF substitution (see Scheme 1) have been designed, synthesized and studied. Previous reports on SBF-based materials for OPV application were indeed exclusively based on the $\mathrm{C} 2$ regioisomers. $^{25}$ Yet, differences in conjugation lengths, molecular shapes and morphological behaviours are expected for both isomers, as recently reported for other 2- and 4-substituted SBF. ${ }^{26,27}$

\section{Results and discussion}

Both molecules have been synthesized following the same approach (Scheme 1), including a Suzuki-Miyaura cross-coupling reaction promoted by palladium catalyst between the boronate derivatives of SBF $\left(\mathbf{1}^{28}\right.$ or $\left.2^{27}\right)$ and the bis-brominated Th-DPPTh-based moiety (3). ${ }^{3}$

As Suzuki-Miyaura cross-coupling reactions using SBF derivatives may sometimes be difficult to perform, different conditions have been screened for this key reaction, first focusing on the SBF4-DPP isomer. A combination of different parameters such as catalyst, ligand or solvent was tested to improve the reaction yield.

Tertiary phosphines $\mathrm{PR}_{3}$, have been employed as ligand in this reaction, with $\mathrm{R}$ being a phenyl $\left(\mathrm{P}(o \text {-tolyl })_{3}\right)$ or a cyclohexyl $\left(\mathrm{P}(\mathrm{Cy})_{3}\right)$ moiety. A better reactivity is obtained by using the ligand $\mathrm{P}(\mathrm{Cy})_{3}$, as expected from its highest electron donating character which helps stabilizing the in situ formed palladium complex (see entry 2 versus entry 4 in Table 1). ${ }^{29}$

Among the different solvents tested, the dioxane/water polar mixture led to best efficiencies (Table 1, entries 5) in regards to the standard xylene/water (Table 1, entries 4) and toluene/water (Table 1, entries 1) mixtures. Finally, the choice of $\mathrm{Cs}_{2} \mathrm{CO}_{3}$ as base, instead of the usual $\mathrm{K}_{2} \mathrm{CO}_{3}$, motivated by its higher solubility in the dioxane/water mixture, led to an even better yield (Table 1, entries 6).

Thus, upon optimization of the catalyst, phosphine ligand and solvent (Table 1), it was possible to set the best conditions leading to a high yield (56\%) of the targeted SBF4-DPP compound. The protocol involves the use of $\mathrm{Pd}_{2} \mathrm{dba}_{3}, \mathrm{P}(\mathrm{Cy})_{3}$ and $\mathrm{Cs}_{2} \mathrm{CO}_{3}$ in a dioxane/water mixture at a temperature of $100{ }^{\circ} \mathrm{C}$ for 24 hours.

For the synthesis of SBF2-DPP, only two conditions were tested (entries 7 and 8 in Table 1), leading to the best yield of 54\% when the optimized protocol used for SBF4-DPP was employed.

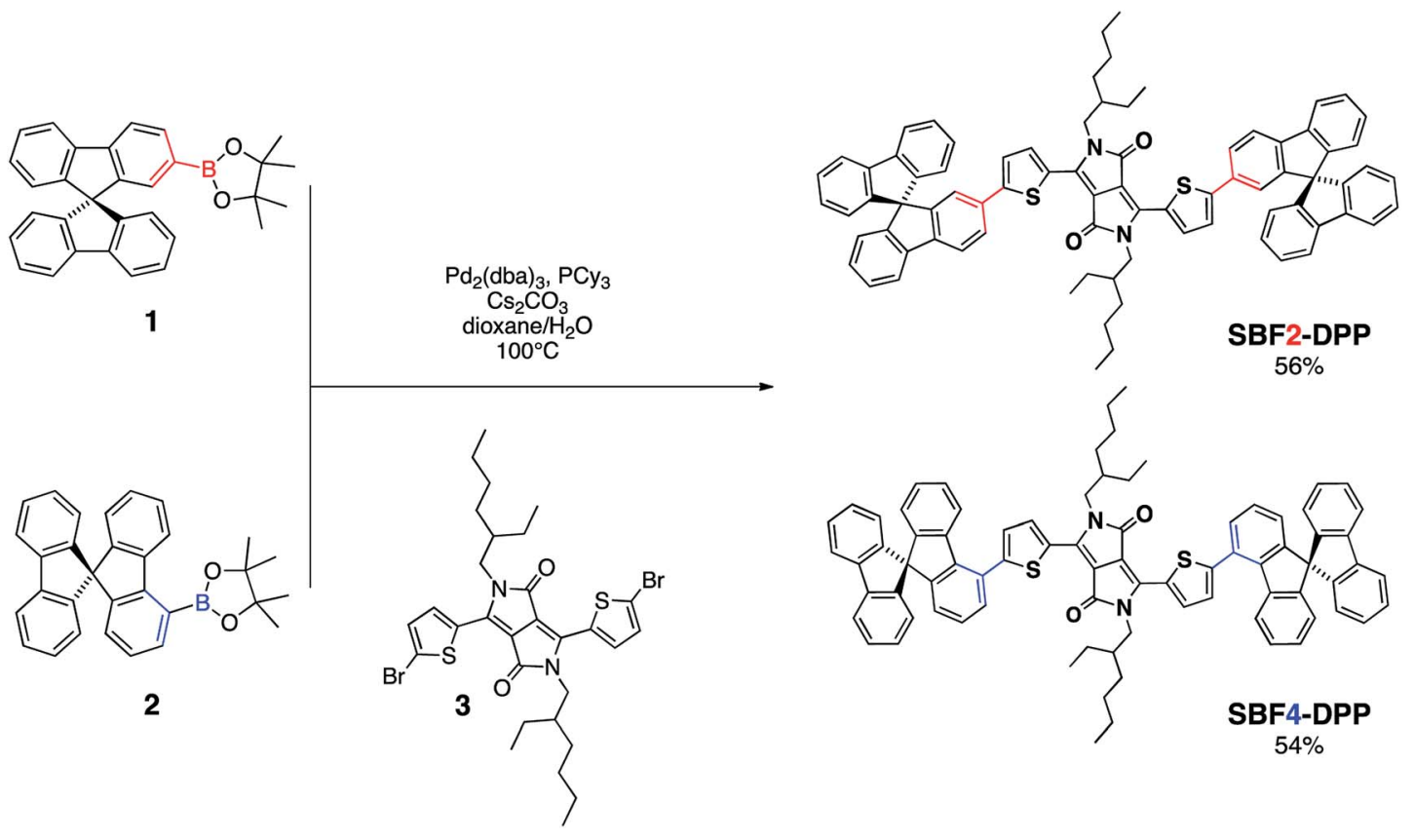

Scheme 1 Synthesis of SBF2-DPP and SBF4-DPP. 
Table 1 Optimization of Suzuki cross-coupling reaction with the C2/C4-dioxoborolane-spirobifluorene unit and the dibrominated diketopyrrolopyrrole-thiophene moiety

\begin{tabular}{|c|c|c|c|c|c|c|}
\hline Entry & Isomer & Catalyst $^{a}$ & Ligand $^{b}$ & Base $^{c}$ & Solvent $10 / 1^{d}$ & Yield $^{e}$ \\
\hline 1 & SBF4-DPP & $\mathrm{Pd}_{2} \mathrm{dba}_{3}$ & $\mathrm{P}(o \text {-tolyl })_{3}$ & $\mathrm{~K}_{2} \mathrm{CO}_{3}$ & Toluene $/ \mathrm{H}_{2} \mathrm{O}$ & $26 \%$ \\
\hline 2 & SBF4-DPP & $\mathrm{Pd}_{2} \mathrm{dba}_{3}$ & $\mathrm{P}(o \text {-tolyl })_{3}$ & $\mathrm{~K}_{2} \mathrm{CO}_{3}$ & Xylene $/ \mathrm{H}_{2} \mathrm{O}$ & $33 \%$ \\
\hline 4 & SBF4-DPP & $\mathrm{Pd}_{2} \mathrm{dba}_{3}$ & $\mathrm{P}(\mathrm{Cy})_{3}$ & $\mathrm{~K}_{2} \mathrm{CO}_{3}$ & Xylene $/ \mathrm{H}_{2} \mathrm{O}$ & $37 \%$ \\
\hline 5 & SBF4-DPP & $\mathrm{Pd}_{2} \mathrm{dba}_{3}$ & $\mathrm{P}(\mathrm{Cy})_{3}$ & $\mathrm{~K}_{2} \mathrm{CO}_{3}$ & Dioxane $/ \mathrm{H}_{2} \mathrm{O}$ & $46 \%$ \\
\hline 6 & SBF4-DPP & $\mathbf{P d}_{2} \mathbf{d b a}_{3}$ & $\mathbf{P}(\mathbf{C y})_{3}$ & $\mathrm{Cs}_{2} \mathrm{CO}_{3}$ & Dioxane $/ \mathbf{H}_{2} \mathbf{O}$ & $56 \%$ \\
\hline
\end{tabular}

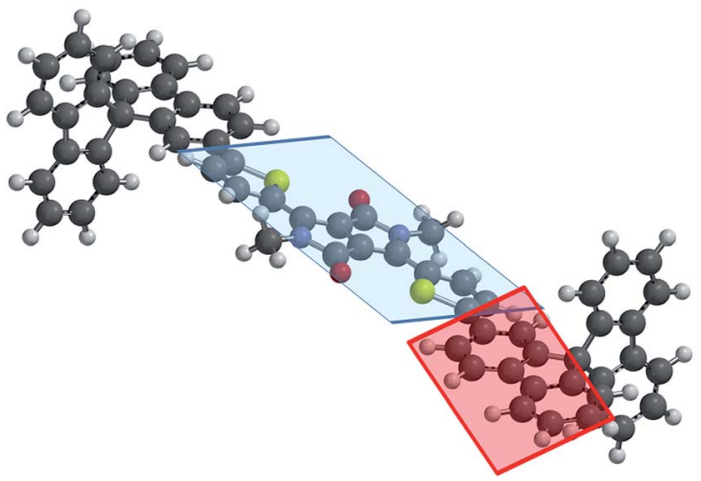

Fig. 1 Minimal energy conformation for the SBF2-DPP molecule including the definition of the angle between the central Th-DPP-Th plane (blue plane) and the plane defined by the conjugated fluorene units of the SBF group (red plane).

Interestingly, despite a very low alkyl side-chain density along the conjugated backbone, both molecules show a high solubility in common organic solvents, such as chloroform and THF, allowing high quality thin films to be obtained by spin-coating. This remarkable solubility promotor effect of the SBF unit can be observed by comparing with other similar molecules where SBF were replaced by pyrene units. ${ }^{24}$ For the latter, much bulkier side-chains were required to bring sufficient solubility for the molecules to be processed into homogeneous films.

Density functional theory (DFT) calculations have been performed using SPARTAN 10 at the B3LYP/6-311+G* level of theory in vacuum on both molecules. For both molecules, the central Th-DPP-Th core is almost planar with a dihedral angle between the central DPP and the adjacent thiophene units in the $6-7^{\circ}$ range. On the other hand, the dihedral angle between the mean plane of this central Th-DPP-Th core (blue plane in Fig. 1) and that of the substituted fluorene unit of the SBF fragment (red plane in Fig. 1) differs from one molecule to the other. Indeed, in SBF2-DPP a dihedral angle of only $25^{\circ}$ has been calculated while it reaches $50^{\circ}$ in SBF4-DPP. This significant difference between the dihedral angles has been assigned to the steric interaction in SBF4-DPP between the hydrogen atoms in the ortho position of the pendant thiophene ring and that of the phenyl unit of the fluorenyl core (position C5)

\section{SBF2-DPP}
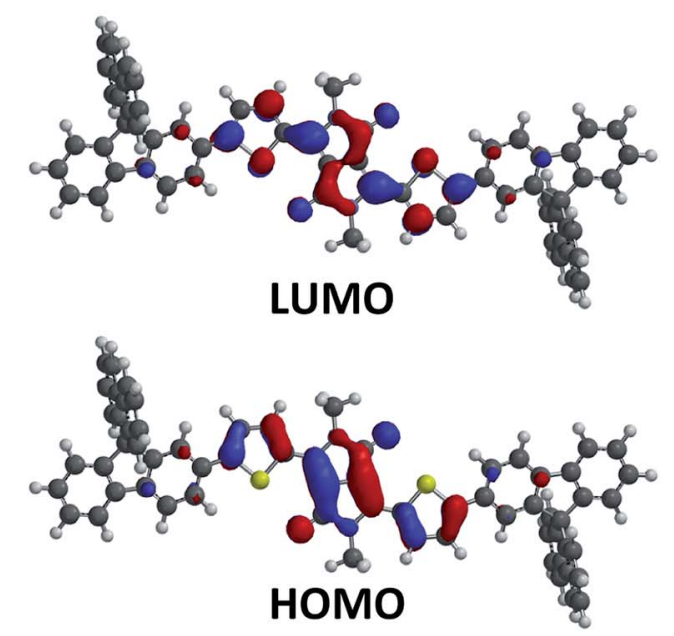

\section{SBF4-DPP}

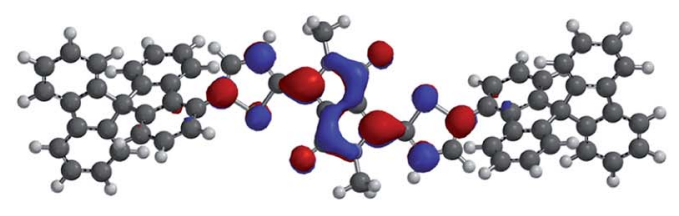

LUMO

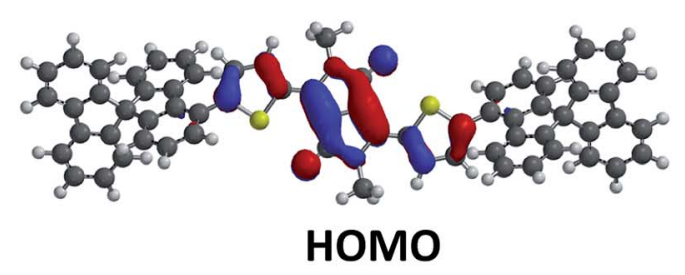

Fig. 2 Calculated LUMO (top) and HOMO (bottom) surface contour plots for SBF2-DPP (left) and SBF4-DPP (right), respectively. 


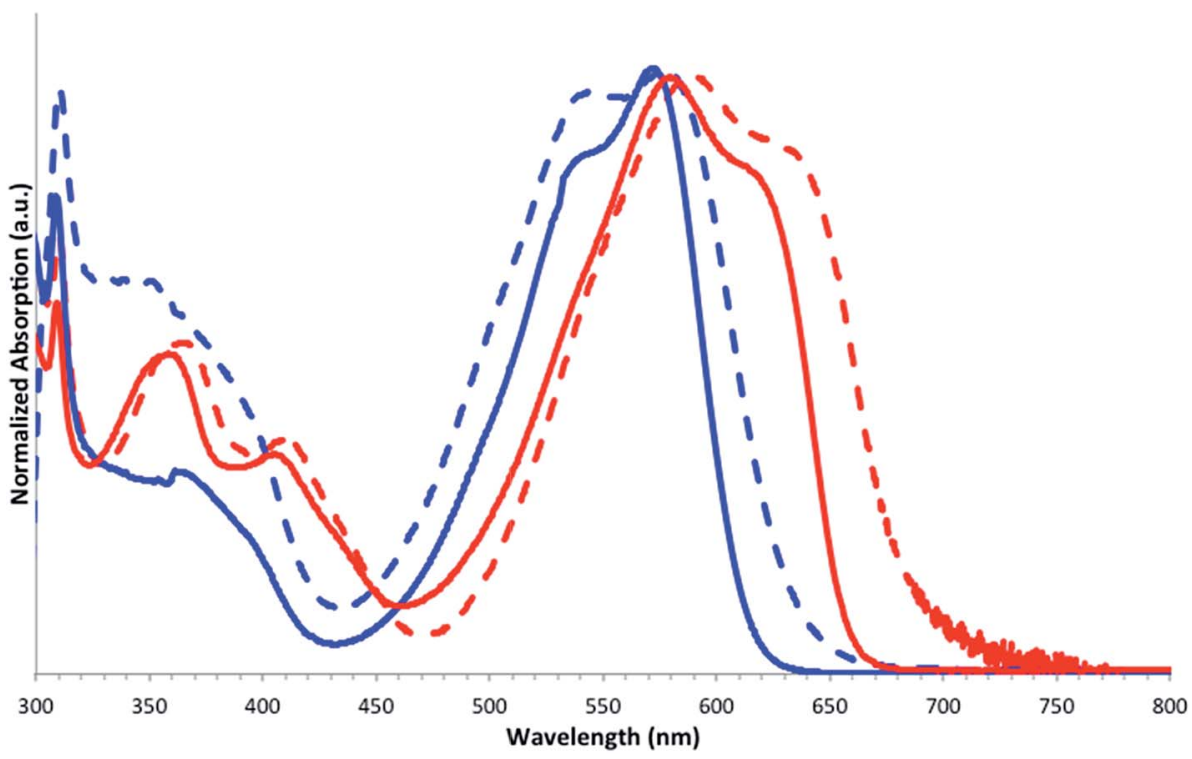

Fig. 3 UV-vis absorption spectra of SBF2-DPP (red) and SBF4-DPP (blue) in chloroform solutions (full line) and in thin films (dashed line).

(see Fig. S2 and related discussion in ESI†). ${ }^{30}$ This angular variation between $\mathrm{C} 2$ - and $\mathrm{C} 4-\mathrm{SBF}$ fragments is at the origin of the restricted $\pi$-conjugation observed in literature for the latter and will have herein remarkable consequences on the electronic properties (see below). ${ }^{27,30}$

The calculated HOMO and LUMO are mainly delocalized for both molecules on the Th-DPP-Th fragment but with a more intense delocalization on the connected fluorene for SBF2-DPP than for SBF4-DPP (Fig. 2). This is the direct consequence of the restricted $\pi$-conjugation of $\mathrm{C} 4-\mathrm{SBF} v$ s. C2-SBF. The calculated LUMO levels are lying at $-2.5 \mathrm{eV}$ below the vacuum level for both molecules while the calculated HOMO levels are situated at -4.7 and $-4.9 \mathrm{eV}$ for SBF2-DPP and SBF4-DPP, respectively, leading to a theoretical bandgap of 2.2 and $2.4 \mathrm{eV}$ for SBF2-DPP and SBF4-DPP, respectively.

Thermal stability and phase behaviour of the two molecules were investigated by thermal gravimetric analysis (TGA), polarizing optical microscopy (POM) and differential scanning calorimetry (DSC). Both molecules present a high thermal stability well above $200{ }^{\circ} \mathrm{C}$ (Fig. S4 in ESI†). SBF2-DPP was found to be an infusible solid before thermal decomposition whereas SBF4-DPP is a crystalline solid turning into the isotropic liquid at approximately $170{ }^{\circ} \mathrm{C}$. The crystalline nature of these two solid phases was confirmed by small-angle X-ray scattering (SAXS), as patterns contain overlapping reflections in the small,

Table 2 Optical absorption properties of the molecules

\begin{tabular}{|c|c|c|c|c|}
\hline \multirow[b]{2}{*}{ Molecule } & \multicolumn{2}{|l|}{ Solution } & \multicolumn{2}{|l|}{ Solid state } \\
\hline & $\begin{array}{l}\lambda_{\max }(\mathrm{nm}) \\
{\left[\varepsilon\left(\mathrm{M} \mathrm{cm}^{-1}\right)\right]}\end{array}$ & $E_{\mathrm{g}}^{\mathrm{opt}}(\mathrm{eV})$ & $\lambda_{\max }(\mathrm{nm})$ & $E_{\mathrm{g}}^{\mathrm{opt}}(\mathrm{eV})$ \\
\hline SBF2-DPP & $572,623[51500]$ & 1.88 & 590,640 & 1.81 \\
\hline SBF4-DPP & $530,570\left[\begin{array}{ll}35 & 000\end{array}\right]$ & 2.02 & 535,580 & 1.95 \\
\hline
\end{tabular}

intermediate and wide-angle regions, with no detectable diffuse signal from partial structural disorder (Fig. S5 in ESI†). Although the induction of mesomorphism was from the beginning unlikely to occur without aliphatic chains on side-cores, one could expect that the molecular self-assembling would be hampered by the steric hindrance of SBF units. The introduction of these globular-shaped end-cappers is finally not detrimental to crystallization. An influence on the thermal behaviour should nevertheless exist since the most irregular-shaped isomer SBF4-DPP is also the one exhibiting the lowest (actually the only accessible) melting transition. Remarkably, despite these high-melting crystalline phases and the presence of only two side-chains on the whole molecule, SBF brings enough solubility to lead to soluble molecules in common solvents.

UV-vis absorption spectra of the molecules in chloroform solution and in thin films are given in Fig. 3. Values are summarized in Table 2.

Both molecules exhibit several absorption bands between 300 and $700 \mathrm{~nm}$. The first thin band recorded at $c a .308 \mathrm{~nm}$ is characteristic of the $\pi-\pi^{*}$ transition of the fluorenyl units. ${ }^{30}$ Four other absorption bands are also detected with maxima recorded around 350, 390 (shoulder), 530 and $570 \mathrm{~nm}$ for SBF4DPP, and around 360, 415, 572 and $623 \mathrm{~nm}$ for SBF2-DPP. Except the first high-energy band, the absorption spectra of the two SBF derivatives present the same shape than that reported in the literature for the central Th-DPP-Th core, ${ }^{31}$ which also possess four maxima at 340, 391, 513 and $548 \mathrm{~nm}$. The low energy absorption band of SBF4-DPP $\left(\lambda_{\max }=570 \mathrm{~nm}\right)$ and SBF2-DPP $\left(\lambda_{\max }=623 \mathrm{~nm}\right)$ is hence clearly red shifted by $22 \mathrm{~nm}$ and $75 \mathrm{~nm}$ respectively compared to that of Th-DPP-Th. ${ }^{31}$ This bathochromic shift of the spectra may be explained by the $\pi$-conjugation extension occurring between the central Th-DPP-Th core and the two SBF units. This shift appears larger for SBF2-DPP than for SBF4-DPP, the former displaying, 
due to the para linkage and the smaller torsion angle, a more efficient conjugation between the SBF fragment and the central Th-DPP-Th core.

Interestingly, both molecules display different behaviours in thin films. The absorption maximum is bathochromically shifted by roughly $20 \mathrm{~nm}$ in solid state for SBF2-DPP, whereas SBF4-DPP shows an overall broadening of the low energy band, resulting in a slight band gap reduction in the solid state. Thus, SBF2-DPP presents a quite standard behaviour going from solution to solid state, with a better conjugation in solid state attributed to an increased intermolecular $\pi$-stacking. Two important features can be deduced from these observations and will have important consequences on the subsequent device performances: (i) despite the presence of the spiro carbon, which usually leads to restricted $\pi$-intermolecular interactions, SBF2-DPP shows the feature of solid-state stacking indicating that 2-substituted SBF units at the periphery of the DPP core do not completely restrict the intermolecular $\pi-\pi$ interactions, (ii) the C4-SBF substitution reduced the intermolecular stacking as SBF4-DPP only displays a very weak gap contraction from solution to solid state (Table 2).

From the onset of absorption in solid state, measured optical bandgaps are 1.81 and $1.95 \mathrm{eV}$ for SBF2-DPP and SBF4-DPP respectively, confirming a better $\pi$-electron delocalization for the former. SBF2-DPP also presents a higher extinction coefficient for its main band $\left(\lambda=623 \mathrm{~nm}, \varepsilon=51500 \mathrm{M} \mathrm{cm}^{-1}\right)$ compared to that of its regioisomer SBF4-DPP $(\lambda=570 \mathrm{~nm}, \varepsilon=$ $35000 \mathrm{M} \mathrm{cm}^{-1}$ ) reflecting again the different optical properties of the two chromophores.

The electrochemical properties of both molecules have been investigated by cyclic voltammetry (CV). The solution of SBF2-DPP was 40 times more diluted than that of SBF4-DPP, leading to higher background currents for the first isomer. For that reason, the CV reported for SBF2-DPP in Fig. 4 has been intentionally limited to the potential range of its electroactivity (for the complete CV curve recorded for SBF2-DPP, see Fig. S6 in $\mathrm{ESI}_{\dagger}^{\dagger}$ ).

SBF4-DPP presents two successive oxidation and reduction waves, with only the first processes being reversible (see Fig. S7 in ESI $\dagger$ ). The peak potentials are measured at 0.97 and $1.23 \mathrm{~V} v s$. SCE in oxidation and at -1.16 and $-1.7 \mathrm{~V} v s$. SCE in reduction. As the first oxidation wave of SBF is known to take place at a higher potential, i.e. $1.69 \mathrm{~V},{ }^{32}$ the two first oxidation waves of SBF4-DPP should be attributed to the Th-DPP-Th core, in agreement (i) with the electrochemistry previously reported for Th-DPP-Th (0.905 and $1.28 \mathrm{~V} v s$. SCE) and (ii) with the present theoretical calculations presented above (HOMO and LUMO are mainly localized on the Th-DPP-Th fragment). Thus, the presence of the SBF units has only a slight effect on the first oxidation potential of SBF4-DPP, with a positive $0.07 \mathrm{~V}$ shift in the anodic direction. The presence of the two SBF units makes nevertheless the reduction easier as shown by the presence of a reversible wave at $-1.29 \mathrm{~V}$, positively shifted by $0.13 \mathrm{~V}$ compared to Th-DPP-Th. ${ }^{31}$

From the onset oxidation and reduction potentials, HOMO and LUMO of SBF4-DPP were estimated at -5.65 and $-3.75 \mathrm{eV}$, giving an electrochemical bandgap of $1.9 \mathrm{eV}$ in line with the optical bandgap measured in $\mathrm{CHCl}_{3}$ solution (2.02 eV). Due to the lower concentration, CV traces recorded for SBF2-DPP were less well defined than those recorded for SBF4-DPP. Only one oxidation and one reduction wave (corresponding maxima at 0.83 and $-0.95 \mathrm{~V}$ ) are observed, showing an easier oxidation and reduction process of SBF2-DPP compared to SBF4-DPP and to Th-DPP-Th. HOMO and LUMO of SBF2-DPP were calculated from the onset potentials at -5.47 and $-4.0 \mathrm{eV}$ giving an electrochemical bandgap of $1.47 \mathrm{eV}$ lower by $0.34 \mathrm{eV}$ from its optical bandgap (1.81 eV) determined in solution. The SBF core seems hence to have a stronger effect on the LUMO energy level than on the HOMO energy level. This tuning of the molecular orbital energy levels leads to a SBF2-DPP electrochemical bandgap $0.43 \mathrm{eV}$ lower than that of SBF4-DPP. This bandgap reduction is significantly larger than that estimated from optical data (0.14 eV, optical transitions recorded in $\mathrm{CHCl}_{3}$ ) and from theoretical calculations ( $0.2 \mathrm{eV}$ without solvent).

Finally it is important to mention that the HOMO, LUMO and bandgap changes observed when comparing SBF4-DPP to SBF2-DPP follow the same trend than those observed from
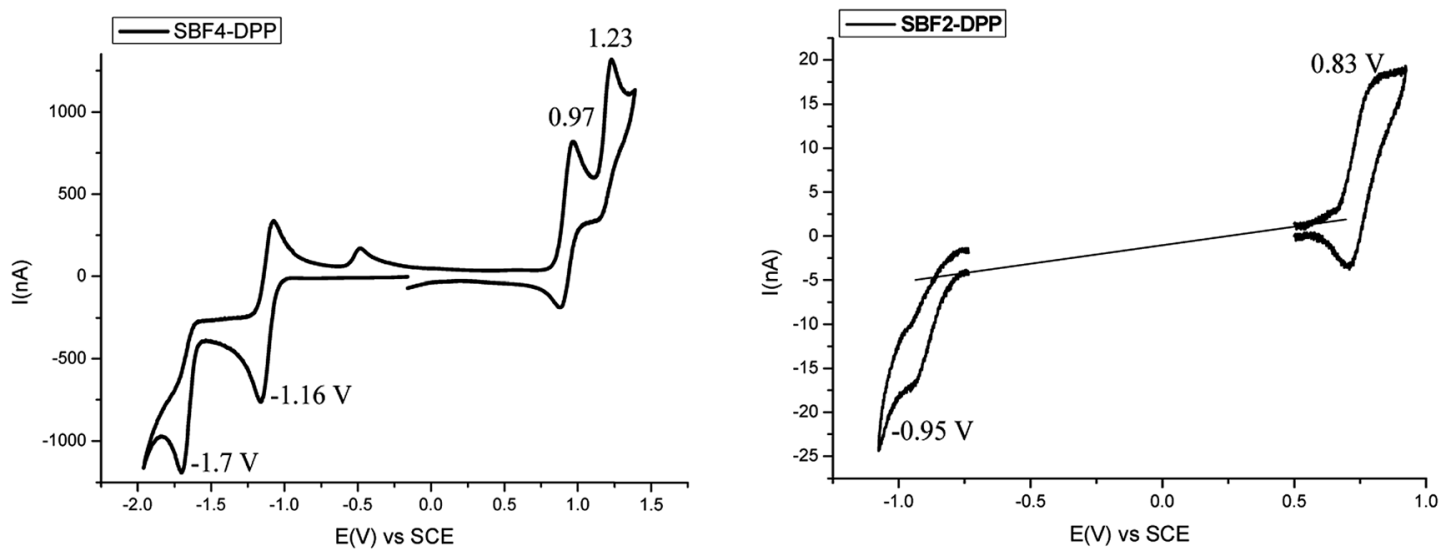

Fig. 4 Cyclic voltammograms of SBF4-DPP (left) and SBF2-DPP (right) recorded in $\mathrm{CH}_{2} \mathrm{Cl}_{2}+0.2 \mathrm{M}$ [NBu 4 ] $\left[\mathrm{PF} \mathrm{F}_{6}\right]$. Platinum working electrode, sweep-rate: $100 \mathrm{mV} \mathrm{s}^{-1}$. 
4-Ph-SBF to 2-Ph-SBF. ${ }^{26}$ This suggests that the impact of the regioisomerism on the electronic properties is only weakly dependent on the SBF substituent nature.

The charge transport was investigated by means of field-effect transistors (FET) and space-charge limited current devices (SCLC). A typical FET output characteristic (bottom contact, bottom gate configuration) for the as-cast SBF4-DPP molecule is displayed in Fig. 5.

For both molecules, an injection barrier is visible in the output characteristics. This is rather expected as the contact work-function (5.1 eV for gold) is far from the HOMO of both molecules $(-5.47$ and $-5.65 \mathrm{eV}$ for SBF2-DPP and SBF4-DPP, respectively). Nevertheless, hole mobilities have been estimated in the linear regime using the usual formalism. Hole mobility values (underestimated due to the injection barrier) are in the $2 \times 10^{-5}$ and $5 \times 10^{-7} \mathrm{~cm}^{2} \mathrm{~V}^{-1} \mathrm{~s}^{-1}$ range for SBF2-DPP and SBF4-DPP, respectively.

Hole mobilities measured by SCLC are for both molecules in the 6-7 $\times 10^{-5} \mathrm{~cm}^{2} \mathrm{~V}^{-1} \mathrm{~s}^{-1}$ range. The SCLC hole mobility is thus significantly higher than the FET hole mobility while the opposite is naively expected from the mobility dependence as a function of the charge-carrier concentration. ${ }^{33}$ This unexpected behaviour could be due to a certain structural anisotropy favouring $\pi$-stacking orientation out of the substrate plane. On the other hand, as FET mobilities are probing a very thin layer close to the oxide/semiconductor interface, the formation of a low-conduction layer on top of the oxide cannot be completely ruled out. Despite all these open questions, the charge-carrier mobilities measured by SCLC reach decent values opening the way for OPV devices elaboration and characterization.

Organic photovoltaic (OPV) devices were elaborated using a standard architecture (anode on the transparent side of the device) with the following structure: ITO/PEDOT:PSS/activelayer/Al. The active layers made up of SBF-based molecular compounds: $\mathrm{PC}_{71} \mathrm{BM}$ blends have been deposited by spincoating from chlorobenzene or chloroform solutions and thermal annealing steps have been performed after the aluminium thermal evaporation. Each OPV device had an active

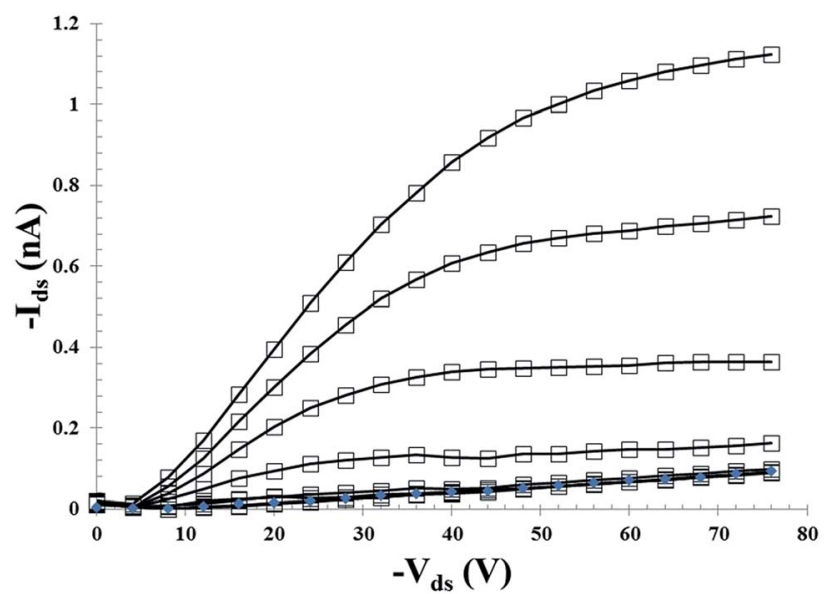

Fig. 5 Output characteristic of an as-cast SBF4-DPP FET with gate voltage ranging from 0 to $-80 \mathrm{~V}$ with a $-10 \mathrm{~V}$ voltage step.
Table 3 Photovoltaic properties of SBF-DPP molecules

\begin{tabular}{llllll}
\hline Molecule & $\begin{array}{l}\text { Molecule : PCBM } \\
\text { ratio }\end{array}$ & $\begin{array}{l}V_{\mathrm{oc}} \\
(\mathrm{V})\end{array}$ & $\begin{array}{l}J_{\mathrm{sc}} \\
\left.(\mathrm{mA} \mathrm{cm})^{-2}\right)\end{array}$ & $\begin{array}{l}\mathrm{FF} \\
(\%)\end{array}$ & $\begin{array}{l}\text { PCE } \\
(\%)\end{array}$ \\
\hline SBF2-DPP & $1: 1.5$ & 0.73 & 3.6 & 31 & 0.8 \\
SBF4-DPP & $1: 3$ & 0.48 & 0.7 & 29 & 0.1
\end{tabular}

area of $12 \mathrm{~mm}^{2}$. Details on OPV device fabrication can be found in the ESI. $\dagger$ Electrical parameters of OPV devices are summarized in Table 3 . The $(J-V)$ curves for the best devices are reported in Fig. 6.

As above mentioned, both compounds show sufficient solubility to be processed from chloroform and to form uniform thin films in blend with $\mathrm{PC}_{71} \mathrm{BM}$.

SBF2-DPP shows a moderate but marked photovoltaic effect with especially a good open circuit voltage $\left(V_{\text {oc }}\right)$ of $730 \mathrm{mV}$. The measured short circuit current density $\left(J_{\mathrm{sc}}\right)$ value for SBF2-DPP is rather low, i.e. $3.6 \mathrm{~mA} \mathrm{~cm} \mathrm{~cm}^{-2}$, despite its moderate bandgap. External quantum efficiency measurements were carried out to calculate $J_{\mathrm{sc}}$. The calculated values were found to be $12 \%$ higher (global tilt) than the $J_{\mathrm{sc}}$ values measured under standard illumination conditions (AM1.5G, $100 \mathrm{~mW} \mathrm{~cm}^{-2}$ ). The fill factor $(\mathrm{FF})$ is low $(31 \%)$ and the $(J-V)$ curves show a strong variation of the current-density as a function of the negative voltage.

SBF4-DPP shows poorer photovoltaic performances with all parameters lower than those found for the SBF2-DPP regioisomer. The combination of a lower mobility (i.e. a lower charge transport ability) with a higher band-gap and a lower extinction coefficient (i.e. a lower photon harvesting ability) are most probably at the origin of the far lower $J_{\text {sc }}$ measured on SBF4-DPP devices. The $V_{\text {oc }}$ value is also $250 \mathrm{mV}$ lower than for the SBF2-DPP regioisomer. Taking into account that $V_{\mathrm{oc}}$ linearly depends on the LUMO (A)-HOMO (D) offset ${ }^{34}$ and that the HOMO level of SBF4-DPP (measured by CV) is $180 \mathrm{mV}$ deeper

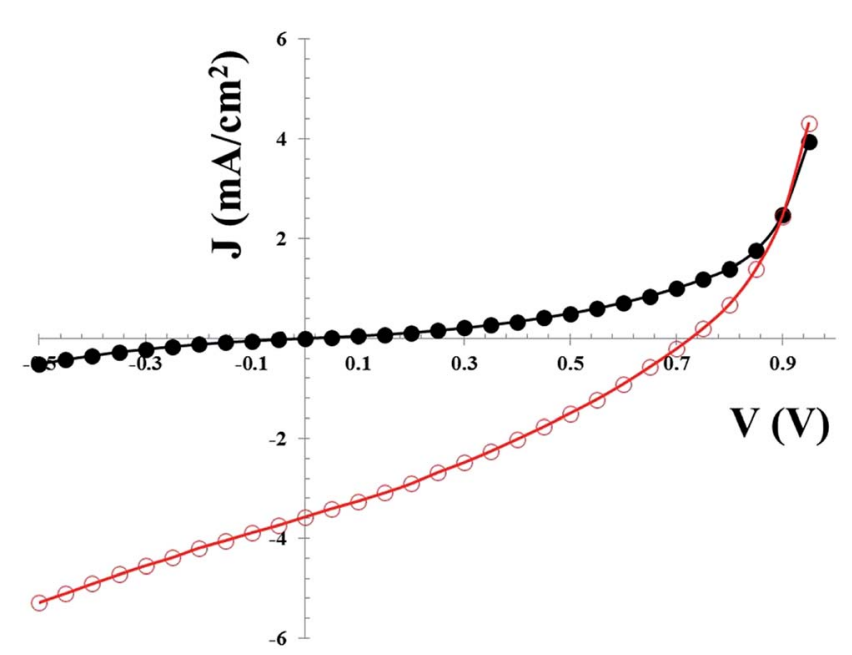

Fig. 6 Current density-voltage curve for the best $\mathrm{BHJ}$ device based on the SBF2-DPP: C $_{71} B M$ blend under darkness (black line and closed symbols) or standard (AM1.5G, $100 \mathrm{~mW} \mathrm{~cm}^{-2}$ ) illumination (red line and open symbols). 
than that of SBF2-DPP, one should rather anticipate a higher $V_{\mathrm{oc}}$ for SBF4-DPP. The strong reduction of the measured $V_{\text {oc }}$ for the SBF4-DPP regioisomer could be due to an unfavourable morphology leading to a high charge-carrier recombination rate. ${ }^{35}$ Moreover, the different regioisomer : $\mathrm{PC}_{71} \mathrm{BM}$ weight ratio needed to obtain the highest photovoltaic properties evidence very different morphologies in blends for the two regioisomers.

\section{Conclusion}

To conclude, this study describes the incorporation of a SBF unit as end capper in a soluble electron donor fragment for photovoltaic applications. It is noteworthy that despite a low alkyl side-chain density grafted along the conjugated backbone (i.e. only two ethylhexyl side-chains onto the central DPP fragment) and high melting temperature crystalline phases, a high solubility has been reached in common solvents, leading to homogeneous thin films formation. This feature highlights the positive effect of the sterically demanding SBF unit on the compound solubility and processability.

Despite low performances in regards to the OPV state-of-theart, this study shows that different molecular packing can be obtained depending of the substitution pattern of the SBF core. In addition, the 2-SBF unit is found to display a better $\pi$-stacking in solid state compared to the 4-SBF isomer, ultimately leading to slightly better OPV performance. We believe that with an optimized molecular design of the overall conjugated backbone, the SBF core can become an interesting scaffold for OPV.

\section{Acknowledgements}

Ibrahim Bulut and Patricia Chávez contributed equally to this work. We thank the Centre National de la Recherche Scientifique (CNRS) and the French National Research Agency (ANR ORION project, ANR-13-PRGE-0001) for financial support. We thank S. Thiery (ISCR, Rennes, funded by ANR HOME OLED, ANR-11-BS07-020-01) for providing compound 1 and compound 2 and Professor T. Heiser for critical reading of this manuscript prior to publication.

\section{References}

1 B. Walker, A. B. Tamayo, X.-D. Dang, P. Zalar, Y. H. Seo, A. Garcia, M. Tantiwiwat and T. Q. Nguyen, Adv. Funct. Mater., 2009, 19, 3063.

2 (a) B. Kan, Q. Zhang, M. Li, X. Wan, W. Ni, G. Long, Y. Wang, X. Yang, H. Feng and Y. Chen, J. Am. Chem. Soc., 2014, 136, 15529; (b) V. Gupta, A. K. K. Kyaw, D. H. Wang, S. Chand, G. C. Bazan and A. J. Heeger, Sci. Rep., 2013, 3, 1965; (c) B. Kan, M. Li, Q. Zhang, F. Liu, X. Wan, Y. Wang, W. Ni, G. Long, X. Yang, H. Feng, Y. Zuo, M. Zhang, F. Huang, Y. Cao, T. P. Russell and Y. Chen, J. Am. Chem. Soc., 2015, 137, 3886.

3 (a) T. Bura, N. Leclerc, R. Bechara, P. Lévêque, T. Heiser and R. Ziessel, Adv. Energy Mater., 2013, 3, 1118; (b) W. Shin,
T. Yasuda, Y. Hidaka, G. Watanabe, R. Arai, K. Nasu, T. Yamaguchi, W. Murakami, K. Makita and C. Adachi, Adv. Energy Mater., 2014, 4, 1400879.

4 (a) T. Bura, N. Leclerc, S. Fall, P. Lévêque, T. Heiser, P. Retailleau, S. Rihn, A. Mirloup and R. Ziessel, J. Am. Chem. Soc., 2012, 134, 17404; (b) A. Mirloup, N. Leclerc, T. Bura, S. Rihn, R. Bechara, P. Lévêque, T. Heiser and R. Ziessel, New J. Chem., 2014, 38, 3644.

5 H. Bürckstümmer, E. V. Tulyakova, M. Deppisch, M. R. Lenze, N. M. Kronenberg, M. Gsänger, M. Stolte, K. Meerholz and F. Würthner, Angew. Chem., Int. Ed., 2011, 123, 11832.

6 (a) G. Wei, S. Wang, K. Sun, M. E. Thompson and S. R. Forrest, Adv. Eng. Mater., 2011, 2, 184; (b) A. Ajayaghosh, Acc. Chem. Res., 2005, 38, 449.

7 C. D. Wessendorf, G. L. Schulz, A. Mishra, P. Kar, I. Ata, M. Weidelener, M. Urdanpilleta, J. Hanisch, E. MenaOsteritz, M. Lindén, E. Ahlswede and P. Bäuerle, Adv. Energy Mater., 2014, 1400266.

8 A. Mirloup, Q. Huaulmé, N. Leclerc, P. Lévêque, T. Heiser, P. Retailleau and R. Ziessel, Chem. Commun., 2015, 51, 14742.

9 S. Roquet, R. de Bettignies, P. Leriche, A. Cravino and J. Roncali, J. Mater. Chem., 2006, 16, 3040.

10 S. Ma, Y. Fu, D. Ni, J. Mao, Z. Xie and G. Tu, Chem. Commun., 2012, 48, 1184.

11 A. Bilge, A. Zen, M. Forster, H. Li, F. Galbrecht, B. S. Nehls, T. Farrell, D. Neher and U. Scherf, J. Mater. Chem., 2006, 16, 3177.

12 (a) K. R. Graham, C. Cabanetos, J. P. Jahnke, M. N. Idso, A. El Labban, G. O. Ngongang Ndjawa, T. Heumueller, K. Vandewal, A. Salleo, B. F. Chmelka, A. Amassian, P. M. Beaujuge and M. D. McGehee, J. Am. Chem. Soc., 2014, 136, 9608; (b) L. Biniek, C. L. Chochos, N. Leclerc, O. Boyron, S. Fall, P. Lêvèque and T. Heiser, J. Polym. Sci., Part A: Polym. Chem., 2012, 50, 1861.

13 Y. Liu, J. Zhao, Z. Li, C. Mu, W. Ma, H. Hu, K. Jiang, H. Lin, H. Abe and H. Yan, Nat. Commun., 2014, 5, 5293.

14 T. P. I. Saragi, T. Spehr, A. Siebert, T. Fuhrmann-Lieker and J. Salbeck, Chem. Rev., 2007, 107, 1011.

15 (a) M. Romain, S. Thiery, A. Shirinskaya, C. Declairieux, D. Tondelier, B. Geffroy, O. Jeannin, J. Rault-Berthelot, R. Métivier and C. Poriel, Angew. Chem., Int. Ed., 2015, 54, 1176; (b) M. Romain, D. Tondelier, J.-C. Vanel, B. Geffroy, O. Jeannin, J. Rault-Berthelot, R. Métivier and C. Poriel, Angew. Chem., Int. Ed., 2013, 52, 14147; (c) C. Poriel, J.-J. Liang, J. Rault-Berthelot, F. Barrière, N. Cocherel, A. M. Z. Slawin, D. Horhant, M. Virboul, G. Alcaraz, N. Audebrand, L. Vignau, N. Huby, G. Wantz and L. Hirsch, Chem.-Eur. J., 2007, 13, 10055; (d) S. Thiery, D. Tondelier, B. Geffroy, E. Jacques, M. Robin, R. Métivier, O. Jeannin, J. Rault-Berthelot and C. Poriel, Org. Lett., 2015, 17, 4682.

16 D. Thirion, M. Romain, J. Rault-Berthelot and C. Poriel, J. Mater. Chem., 2012, 22, 7149.

17 C. Poriel, J. Rault-Berthelot, D. Thirion, F. Barrière and L. Vignau, Chem.-Eur. J., 2011, 50, 14031. 
18 J.-H. Xie and Q.-L. Zhou, Acc. Chem. Res., 2008, 41, 581.

19 C. Poriel, Y. Ferrand, P. Le Maux, J. Rault-Berthelot and G. Simonneaux, Synth. Met., 2008, 158, 796.

20 C. Poriel, Y. Ferrand, P. Le Maux, J. Rault-Berthelot and G. Simonneaux, Inorg. Chem., 2004, 43, 5086.

21 F. Moreau, N. Audebrand, C. Poriel, V. Moizan-Baslé and J. Ouvry, J. Mater. Chem., 2011, 21, 18715.

22 Y. G. Wu, J. Y. Zhang, Z. P. Fei and Z. S. Bo, J. Am. Chem. Soc., 2008, 130, 7192.

23 (a) S.-W. Liu and C.-F. Lin, J. Mater. Res., 2013, 28, 1442; (b) C.-Y. Chan, Y.-C. Wong, H. L. Wong, M. Y. Chan and V. W.-W. Yam, J. Mater. Chem. C, 2014, 2, 7656; (c) X.-F. Wu, W.-F. Fu, M. Shi, F. Kiu, H.-Z. Chen, J.-H. Wan and T. P. Russell, Adv. Funct. Mater., 2015, 25, 5954.

24 O. P. Lee, A. T. Yiu, P. M. Beaujuge, C. H. Woo, T. W. Holcombe, J. E. Millstone, J. D. Douglas, M. S. Chen and J. M. J. Fréchet, Adv. Mater., 2011, 23, 5359.

25 M. Wang, C. Li, A. Lv, Z. Wang and Z. Bo, Macromolecules, 2012, 45, 3017.

26 S. Thiery, C. Declairieux, D. Tondelier, G. Seo, B. Geffroy, O. Jeannin, R. Métivier, J. Rault-Berthelot and C. Poriel, Tetrahedron, 2014, 70, 6337.
27 S. Thiery, D. Tondelier, C. Declairieux, B. Geffroy, O. Jeannin, R. Métivier, J. Rault-Berthelot and C. Poriel, J. Phys. Chem. C, 2015, 119, 5790.

28 Y.-Y. Lyu, J. Kwak, W. S. Jeong, Y. Byun, H. S. Lee, D. Kim, C. Lee and K. Char, Adv. Funct. Mater., 2009, 19, 420.

29 R. Martin and S. L. Buchwald, Acc. Chem. Res., 2008, 41, 1461. 30 S. Thiery, D. Tondelier, C. Declairieux, G. Seo, B. Geffroy, O. Jeannin, R. Métivier, J. Rault-Berthelot and C. Poriel, J. Mater. Chem. C, 2014, 2, 4156.

$31 \mathrm{H}$. Bürckstümmer, A. Weissenstein, D. Bialas and F. Würthner, J. Org. Chem., 2011, 76, 2426.

32 C. Poriel, J. Rault-Berthelot and D. Thirion, J. Org. Chem., 2013, 78, 886.

33 S. Fall, L. Biniek, Y. Odarchenko, D. V. Anokhin, G. de Tournadre, P. Lévêque, N. Leclerc, D. A. Ivanov, O. Simonetti, L. Giraudet and T. Heiser, J. Mater. Chem. C, 2016, 4, 286.

34 M. C. Scharber, D. Mühlbacher, M. Koppe, P. Denk, C. Waldauf, A. J. Heeger and C. J. Brabec, Adv. Mater., 2006, 18, 789.

35 (a) J. Nelson, J. Kirkpatrick and P. Ravirajan, Phys. Rev. B: Condens. Matter Mater. Phys., 2004, 69, 035337; (b) N. K. Elumalai and A. Uddin, Energy Environ. Sci., 2016, 9, 391. 